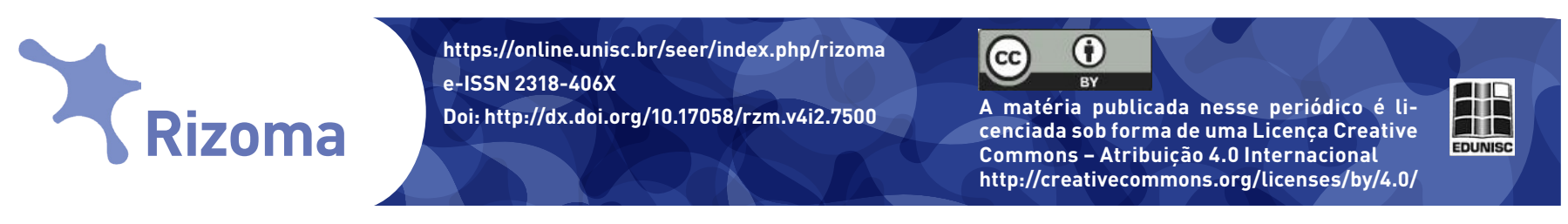

\title{
A jornada do herói em organizações do terceiro setor
}

\section{Resumo}

Este estudo tem como objetivo identificar os heróis em organizações do terceiro setor, com base na análise realizada em três organizações do Rio Grande do Sul. Esta pesquisa exploratória qualitativa, utilizouse de levantamento bibliográfico, observação participante, pesquisa documental e entrevistas em profundidade. Ao final desse processo, relacionou-se as trajetórias dos heróis com jornada do herói estudada por Joseph Campbell e conclui-se que uma mesma organização pode ter vários heróis.

Palavras-chave: cultura organizacional; jornada do heróis; terceiro setor.

\begin{abstract}
This study aims to identify the heroes in third sector organizations, based on the analysis carried out in three of Rio Grande do Sul organizations. This qualitative exploratory study, we used a literature review, participant observation, documentary research and in-depth interviews. At the end of this process, related to the paths of the heroes with the hero's journey studied by Joseph Campbell and it is concluded that a single organization can have multiple heroes.
\end{abstract} Keywords: organizational culture; journey of the heroes; third sector.

\section{Resumen}

Este estudio tiene como objetivo identificar los héroes en las organizaciones del tercer sector, basado en el análisis llevado a cabo en tres de Rio Grande do Sul organizaciones. Este estudio cualitativo exploratorio, se utilizó una revisión de la literatura, la observación participante, la investigación de archivo y entrevistas en profundidad. Al final de este proceso, relacionado con las trayectorias de los héroes con el viaje del héroe estudiados por Joseph Campbell y se concluye que una sola organización puede tener varios héroes.

Palabras clave: cultura de la organización; viaje del héroes; tercer sector.

Caroline Delevati Colpo' Bianca Cunha Correa ${ }^{2}$ Ingrid Humia ${ }^{3}$

\begin{abstract}
1 Professora dos Cursos de Comunicação Social da Universidade Feevale- Novo Hamburgo/

RS. Doutora em Comunicação Social: linha de pesquisa Práticas Profissionais e Processos Sociopolíticos nas Mídias e na Comunicação das Organizações - PUC/RS. Mestre em Desenvolvimento Regional - UNISC. Graduada em RelaçõesPúblicas- UFSM.
\end{abstract}

2 Graduada em Relações Públicas.

3 Graduada em Relações Públicas. 

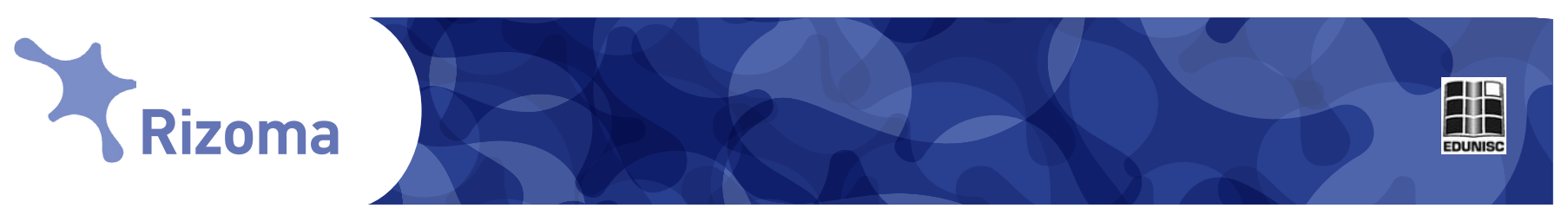

\section{Introdução}

Este estudo aborda os heróis de organizações do terceiro setor e as jornadas que desenvolvem no contexto organizacional. Estes heróis organizacionais, muitas vezes, são os responsáveis por conquistar apoiadores, voluntários e admiradores, através das atividades e ações que praticam na sua jornada. Baseado em pesquisa realizada com três organizações do terceiro setor do Rio Grande do Sul, este estudo busca analisar como é constituída a jornada dos heróis na cultura das organizações do terceiro setor. As organizações estudadas são: Apata, modelo de voluntariado pela causa animal, o Lar Colmeia, que atende crianças e adolescentes que sofreram algum tipo de violência, abandono ou abuso, e o Projeto Criança Cidadã, que atende jovens em situação de vulnerabilidade social e procura mantê-los longe das drogas e da criminalidade. Para que esta pesquisa, exploratória qualitativa, fosse realizada utilizou-se levantamento bibliográfico, técnicas de observação participante, pesquisa documental e entrevistas em profundidade.

Através da identificação do papel do herói na cultura das organizações estudadas, foi possível enxergar o herói de cada uma das organizações e relacionar suas trajetórias pessoais e profissionais com a jornada do herói de Joseph Campbell $(2003,2007)$. Ainda, foi possível fazer uma comparação entre os heróis das organizações e comprovar que eles são figuras fundamentais para a existência das mesmas, assim como, identificou-se diversas semelhanças entre os heróis nas culturas das organizações do terceiro setor.

\section{Organizações do terceiro setor}

O terceiro setor é o conjunto de entidades filantrópicas, não governamentais e sem fins lucrativos que busca, através de suas atividades, potencializar os valores básicos para a população como a cidadania, a liberdade e a dignidade. Segundo Fernandes (1994) no Brasil, o terceiro setor tem sua origem em 1956, no estabelecimento da Caritas, uma organização comunitária da Igreja Católica com atuação em diversos países. Embora, possa ser considerado um campo amplo e em pleno crescimento no Brasil, o terceiro setor ainda enfrenta várias dificuldades para se desenvolver e conseguir os reais benefícios que busca. Entre as dificuldades estão a falta de apoio financeiro e problemas na estrutura organizacional.

Camargo (2001) cita os principais tipos de organizações que compõem o terceiro setor: as associações, formadas por um grupo de pessoas sem fins lucrativos com o objetivo comum de oferecer um determinado serviço: as fundações que se concretizam da vontade altruísta de alguém em destinar seu patrimônio, ou parte dele, em benefício de uma comunidade ou grupo que necessita de apoio; os sindicatos, que são a união de pessoas com o objetivo "de defender, estudar e coordenar seus interesses individuais e profissionais" (CAMARGO, 2001, p. 42); as cooperativas, consideradas como "associação autônoma de pessoas que se unem, voluntariamente, para 


\section{$\gamma_{\text {Rizoma }}$}

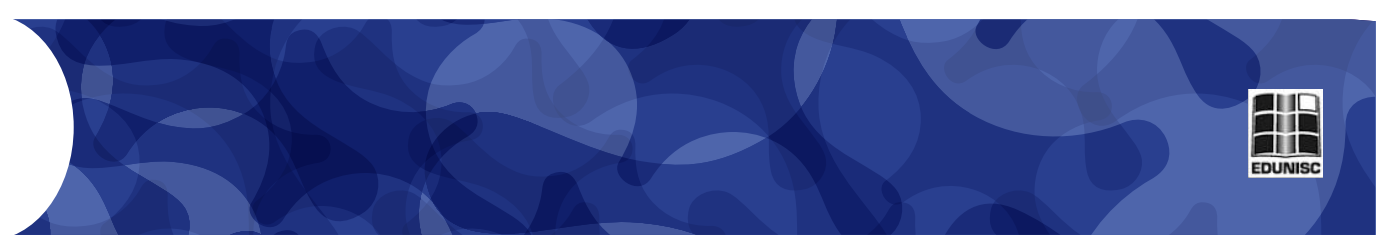

satisfazer aspirações [...] por meio da criação de uma sociedade democrática e coletiva" (CAMARGO, 2001, p. 47). São listadas também as igrejas, que têm o objetivo de transmitir valores como solidariedade, amor ao próximo, ética e responsabilidade social; e as ONGs (organizações não governamentais) que são espaços coletivos de participação da sociedade civil que agem como fiscalizadores do gerenciamento da coisa pública.

Todos este tipos de organizações do terceiro setor procuram se estabelecer buscando melhores condições de vida para a população, tentando, muitas vezes, exercer atividades que até então eram de responsabilidade do Estado, mas que não estavam sendo desenvolvidas em sua totalidade. Segundo Peruzzo (2007, p. 57), "a sociedade civil parece assumir seu papel histórico de não apenas esperar que o Estado a atenda em suas necessidades, mas de fazer sua parte na luta para democratizar a cidadania".

Com isso, pode-se dizer que atualmente o terceiro setor desenvolve suas atividades combatendo o paternalismo do Estado e o individualismo social, integrando a sociedade civil com as problemáticas e soluções sociais. Parafraseando Camargo (2001), o papel do terceiro setor é atuar como agente de transformação social, que por sua vez, presta serviços em benefício coletivo e consegue construir uma consciência que busca urgência em reverter os indicadores sociais.

Com o terceiro setor se desenvolvendo no Brasil, o número de instituições ${ }^{4}$ buscando melhorias para suas comunidades vem aumentando ano após ano, e é possível encontrar muitas iniciando suas atividades ou tentando se consolidar. Por conta desse cenário, as organizações do terceiro setor necessitam de símbolos $^{5}$ que personifiquem seus valores. Essa função simbólica pode ser executada pelos heróis organizacionais que, neste contexto, surgem como sujeitos capazes de fortalecer a cultura organizacional, motivando e despertando potencialidades dentro das próprias organizações e também no público por elas atendido, personificando valores e criando modelos comportamentais.

\section{Heróis organizacionais e a jornada do herói}

A cultura organizacional pode seguir a base de conceitos utilizada pela antropologia cultural, que abriu portas para o estudo do simbólico nas organizações, possibilitando o uso de novas metodologias para entendimento do que constitui a cultura em uma organização. A antropologia cognitiva define cultura como "o conjunto dos conhecimentos que são compartilhados entre os membros de um mesmo grupo ou sociedade" (FREITAS, 2012, p.12), ou ainda organizações. Conforme a antropologia simbólica, o destaque da cultura não se dá apenas sobre os conhecimentos, mas também "sobre os significados compartilhados" (FREITAS, 2012, p.12). Assim, a cultura organizacional pode ser constituída por símbolos criados e legitimados, que servem de exemplos norteadores, para definir 

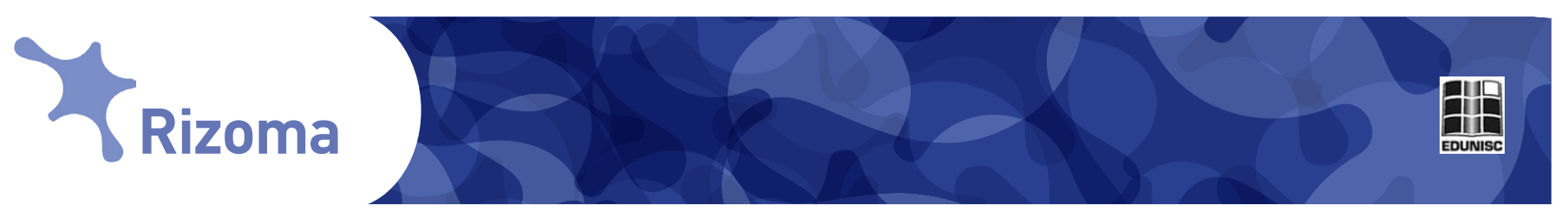

a forma de pensar, tratar e agir de determinada organização. Dentre estes símbolos, é possível identificar o herói.

$\mathrm{Na}$ abordagem de Freitas (1991), os heróis personificam os valores e condensam a força da organização e podem ser os responsáveis pela sua criação. Os heróis têm a coragem e persistência de "fazer aquilo que todos almejam, porém, tem medo de tentar" (FREITAS, 1991, p. 31). Segundo Joseph Campbell (2007, p. 13) o herói pode ser caracterizado como:

O homem ou mulher que conseguiu vencer suas limitações históricas pessoais e locais e alcançou formas normalmente válidas, humanas. As visões, ideias e inspirações dessas pessoas vem diretamente das fontes primárias da vida e do pensamento humano. Eis por que falam com eloquência, não da sociedade e da psique atuais, em estado de desintegração, mas da fonte inesgotável por intermédio da qual a sociedade renasce.

Ainda segundo Campbell (2007), o herói precisa passar por uma jornada para se tornar herói. Esta jornada vai desde o momento de sua partida até o seu retorno, no qual possui os conhecimentos e os poderes que adquiriu ao longo da jornada. Os estágios dessa jornada, segundo Campbell (2007), iniciam no mundo comum, no qual o herói vive antes da história começar. Então, ocorre o chamado da aventura, que é um problema ou um desafio que se apresenta a ele. Primeiro, o herói, geralmente pelo medo, recusa ou demora a aceitar o chamado. Depois, o herói encontra-se com um mentor, que o faz aceitar o chamado e o treina para a aventura. A partir desse momento, o herói abandona o mundo comum para entrar no mundo especial ou mágico. Nesse novo mundo, o herói enfrenta seus primeiros testes, provações, encontra aliados e luta contra inimigos. Desta forma, ele aprende as normas do novo mundo e, por consequência, ele adquire os êxitos que ele tem durante as provações. Após isso, ele passa por uma nova provação, ainda mais difícil e traumática, considerada a maior crise da aventura, uma crise de vida ou morte. Após enfrentar a morte e o medo, ele ganha uma recompensa, o elixir. O herói, então, inicia seu caminho de volta, no qual ele deve retornar para o mundo comum. Neste caminho ocorre a ressurreição, outro teste, no qual ele enfrenta a morte e deve usar tudo o que ele aprendeu. Encerrando a jornada, ocorre o regresso, quando ele volta para casa e utiliza o elixir para ajudar a todos no mundo comum. 


\section{$Y_{\text {Rizoma }}$}

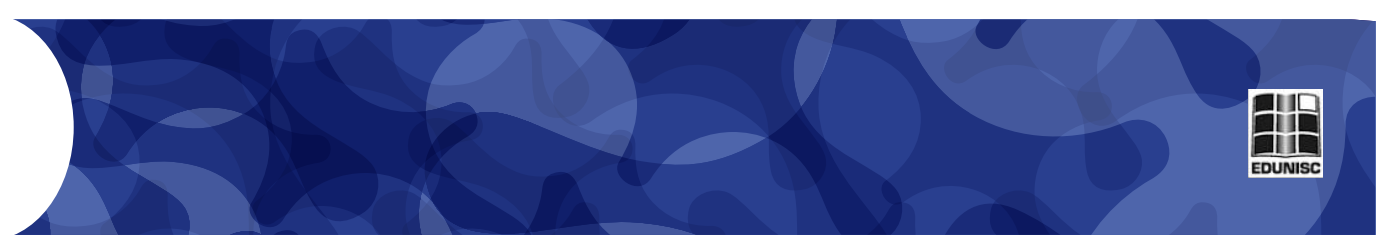

Figura 1: Os doze estágios da Jornada do Herói
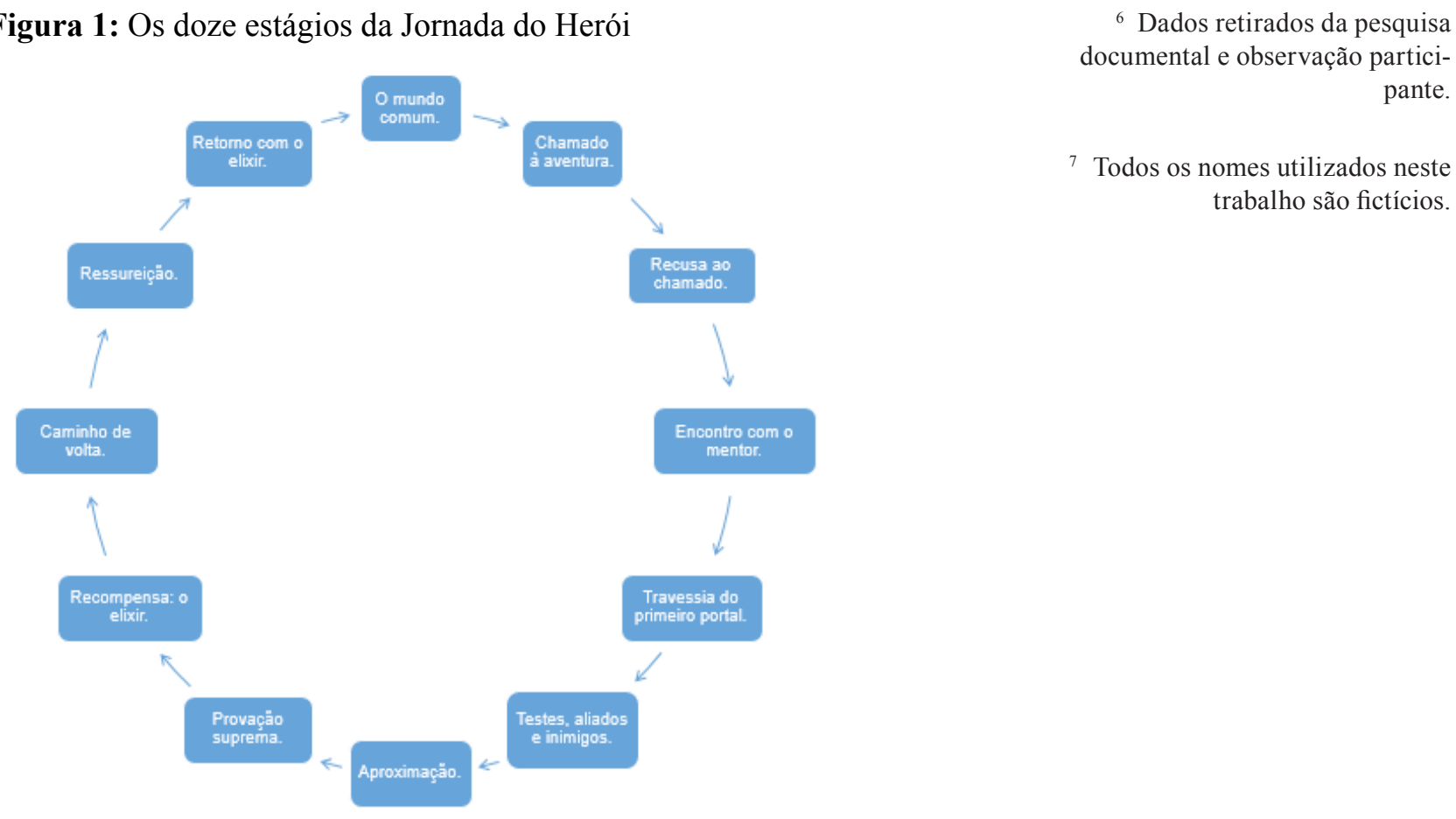
trabalho são fictícios.

Fonte: CAMPBELL, Joseph - O Herói de Mil Faces (2007)

O herói das organizações do terceiro setor não necessariamente passa, ou passou, por todos os passos dessa jornada. Mas, em algum ponto de sua vida, a sua história pode se assemelhar com alguns desses grandes personagens.

\section{Análise da cultura das organizações do terceiro setor}

A análise da cultura das organizações do terceiro setor se faz necessária neste estudo, para identificar elementos que constituem os heróis no contexto organizacional. A primeira organização do terceiro setor analisada neste trabalho foi a Apata, Associação Protetora dos Animais de Taquara. Esta organização foi fundada em $2003^{6}$ através da união de alguns protetores de animais que agiam de forma independente pela causa, resgatando, tratando e doando animais de rua. Para Camargo (2001), as associações são formadas por um grupo de pessoas sem fins lucrativos com o objetivo comum de oferecer um determinado serviço. A Apata não possui funcionários remunerados e nem sede própria, contando com alguns voluntários com dedicação parcial. Para manter-se, depende de doações, do lucro de eventos promovidos e de produtos vendidos, das mensalidades pagas por alguns associados e de um auxílio da Prefeitura.

Para identificar o herói organizacional, alguns elementos da cultura organizacional da Apata foram abordados através de entrevistas. As entrevistadas foram $\mathrm{Joana}^{7}$, voluntária fixa, Maria, que iniciou ajudando esporadicamente e se tornou uma voluntária fixa, e Ana, uma adotante. Questionada sobre as qualidades da organização, Joana afirma que os três principais 

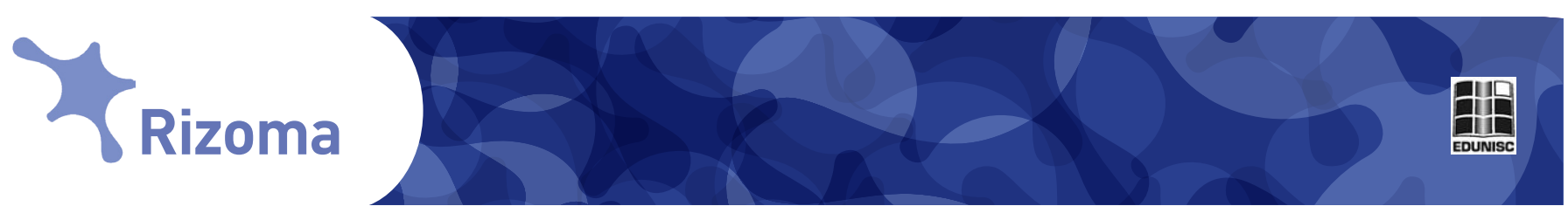

pontos positivos são os voluntários, pois "todos estão focados no mesmo ideal de respeito pela vida animal"; o pioneirismo, pelas formas de arrecadar dinheiro, como os eventos realizados pela entidade e os produtos vendidos; e a comunicação, pela ação conscientizadora na comunidade. Para Maria, a melhor qualidade é a organização, em que todos os casos são discutidos e decididos em equipe. Já Ana, acredita que a maior qualidade da Apata é a vontade de ajudar os animais. Entre os problemas, é possível identificar a falta de tempo dos voluntários, principalmente para criar projetos mais interessantes para captação de recursos. Esse cenário, de escassez de recursos e problemas na estrutura organizacional, é comum nas organizações do terceiro setor. Segundo Camargo (2001) o terceiro setor precisa, para alcançar o crescimento, desenvolver estratégias eficazes de captação de recursos e administrar a gestão de profissionais, voluntários e espaços físicos.

Joana elege três coisas que todos valorizam na Apata: credibilidade, dedicação e transparência. Relacionando com a teoria de Freitas (2012, p. 16), pode-se identificar esses três itens como os principais valores da organização, caracterizados como "aquilo que é importante para o sucesso da organização e devem ser considerados guias para o comportamento organizacional no dia-a-dia".

A segunda organização do terceiro setor pesquisada neste trabalho foi o Lar Colmeia que é um abrigo em sistema de casas-lares, cada casa com um casal de pais sociais, que cuida de até 10 crianças ou adolescentes, em situação de vulnerabilidade física, social e emocional ${ }^{8}$. Situada em Campo Bom, no Rio Grande do Sul, é uma entidade civil de caráter filantrópico, sem fins lucrativos, fundada em 1993 pelo casal canadense Jerilyn Bayer e Ken Bayer. Segundo Camargo (2001), o Lar Colmeia pode ser considerado uma fundação, pois é concretizada da vontade altruísta de alguém em destinar seu patrimônio, ou parte dele, em benefício de uma comunidade ou grupo que necessita de apoio. As crianças que participam do Lar Colmeia precisam estar na faixa etária de 0 a 12 anos e podem permanecer até completarem 18 anos de idade, se ainda não tiverem constituído família, ou não tiverem nenhum amigo ou familiar com qual possam viver. Quando completar 18 anos, o jovem é transferido para a casa de transição, ainda dentro do Lar, na qual precisa trabalhar, estudar, economizar parte da renda e procurar uma forma de moradia para criar sua independência.

Através de entrevistas com o Ricardo, diretor do Lar, Marta, mãe social e Sara, adolescente atendida pela organização, buscou-se alguns elementos da cultura organizacional do Lar Colmeia. Questionado sobre o que é considerado bom na organização, Ricardo identifica o investimento em qualidade de vida e no futuro das crianças atendidas. Em contraponto, relata que não é boa a falta de desejo de mudança de alguns jovens atendidos. "Eles não são impactados por tudo aquilo que fazemos com eles, e alguns acabam deixando o Lar, tornando-se pessoas como os pais deles foram" relata Ricardo. Marta concorda com Ricardo.

O diretor afirma que o principal diferencial da entidade é poder vivenciar um verdadeiro ambiente familiar. "Damos para as crianças a oportuni- 


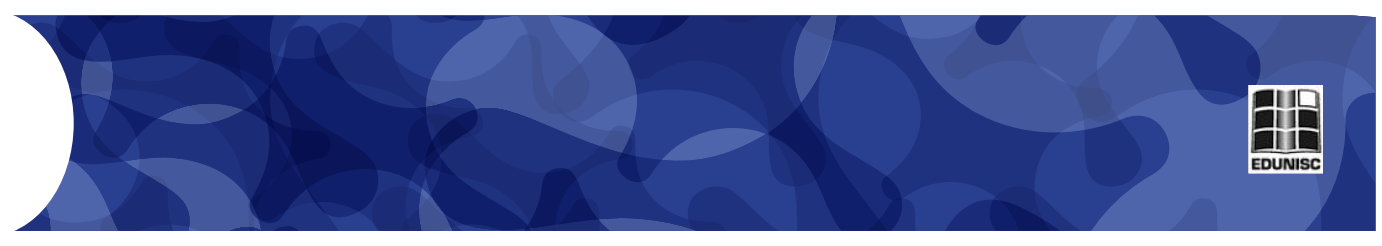

dade de terem uma nova família, que irá ser uma referência que elas nunca tiveram", afirma. Pode-se identificar que esse é um dos principais valores da cultura do Lar Colmeia, o que segundo Freitas (2012), é o elemento mais importante da cultura organizacional e mostra o que a organização enxerga como sucesso. Ilustrando as coisas mais valorizadas pelo Lar Colmeia, Ricardo relata em primeiro lugar a prática de amor, em segundo a transparência absoluta da área financeira da instituição, e por fim, a visão compartilhada por todos, de doação de parte de suas vidas em benefício das crianças. Ricardo relata que, o que é mais criticado na organização, é a discriminação vivenciada pelas crianças fora do Lar. A mãe social concorda com a questão quando afirma que as crianças sofrem preconceito. Já Sara afirma que até o momento não passou por nenhuma situação de discriminação.

Ao analisar o Lar como um todo, é possível identificar, principalmente através das entrevistas, que o seu principal valor de cultura organizacional é oferecer para as crianças um verdadeiro ambiente familiar, algo que foge do padrão de casas de passagens. Segundo Freitas (2012), os valores mostram o que a organização enxerga como positivo e, por isso, precisa valorizar estes elementos.

A terceira e última organização analisada para este trabalho foi o Projeto Criança Cidadã que é uma organização não governamental, sem fins lucrativos, e segundo Camargo (2001), são espaços coletivos de participação da sociedade civil que agem como fiscalizadores do gerenciamento da coisa pública. Esta organização está inserida no bairro 25 de Julho, na cidade de Campo Bom, Rio Grande do Sul e foi fundada pelo casal Renato e Bruna. Atende crianças e adolescentes em situação de vulnerabilidade social, oferecendo oficinas de música, dança, inglês, técnicas agrícolas, artesanato, informática e futsal. Ao completar a idade máxima de 16 anos, os adolescentes precisam se desligar do projeto, sem ter assistência para o mercado de trabalho. O projeto se sustenta basicamente por doações fixas e esporádicas.

Buscando identificar a cultura organizacional do Projeto Criança Cidadã, foi realizada uma entrevista com Renato, diretor da organização, João, uma criança atendida pelo projeto e seus pais, Simone e Pedro. Questionado sobre o que é bom na organização, Renato diz que o melhor é poder ajudar crianças e adolescentes a se valorizarem como sujeito. Pode-se identificar que este é o principal valor da organização, que funciona "como o coração da cultura organizacional, [...] e definem o sucesso em termos concretos para os empregados e estabelecem os padrões que devem ser alcançados" (FREITAS, 2012, p. 16). O menino João gosta das oficinas e afirma ter aprendido muito no projeto. Os pais do menino acreditam que tudo o que as crianças aprendem é muito bom. Além disso, sentem-se seguros em deixar seu filho na organização. Falando sobre o que é ruim, Renato relata a questão da estrutura física do projeto, no qual as crianças passam calor no verão e frio no inverno. Fala ainda da falta de materiais, falta de profissionais mais qualificados para atender as crianças, falta de auxílio psicológico e poucas condições financeiras para remunerar melhor os colaboradores. Os pais não conseguem identificar nada que seja ruim. 

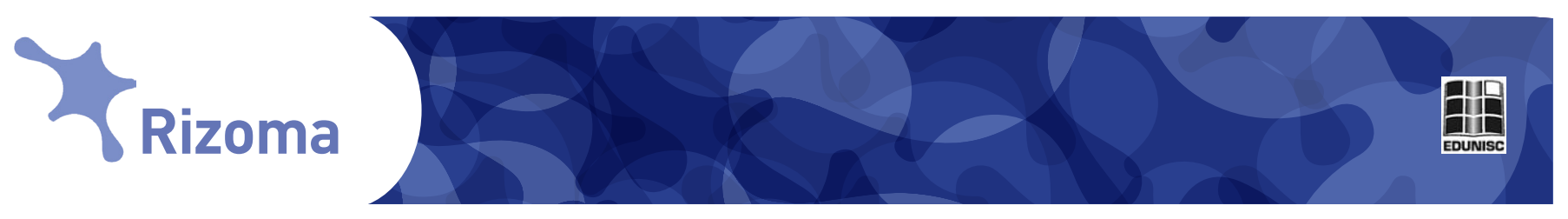

Pensando nos diferenciais da organização, Renato não identifica fatores que possam ser destacados. Apenas ressalta que é o único projeto social da cidade que atende as crianças de segunda a sexta. Quanto às coisas mais importantes e valorizadas no Projeto Criança Cidadã, ele identifica o respeito de um pelo outro, a amizade construída dentro do projeto entre as próprias crianças e também entre as crianças, os colaboradores e os voluntários.

Questionado sobre um símbolo que identifique a organização, Renato fala de esperança. Quando nem os pais, nem a comunidade acreditam mais nas crianças, eles acreditam e fazem de tudo para que a criança em vulnerabilidade social tenha uma vida melhor. O símbolo faz parte das crenças e pressupostos da organização que, segundo Freitas (2012), mostra o que é entendido como verdade na cultura da organização.

\begin{abstract}
Dentre os pressupostos mais comuns, podemos citar: "o principal compromisso de uma empresa é com os seus acionistas", "a missão da medicina é salvar vidas", "é na escola que se aprende" etc. Introjetamos essas mensagens e elas se tornam verdades que não serão mais questionadas, problematizadas, politizadas. Elas ficam congeladas no tempo e no espaço como se fossem absolutas e não relativas a uma época, a um contexto histórico específico e ao conhecimento disponível naquele dado momento. (FREITAS, 2012, p. 18).
\end{abstract}

Assim, a esperança é o símbolo que está na crença da cultura organizacional do Projeto Criança Cidadã. Com isto, atua como forma simbólica para muitos indivíduos, integrando a organização de forma consensual para gerar significados nos sujeitos que afeta.

Estes elementos da cultura organizacional identificados nas organizações do terceiro setor, aqui estudadas, irão ajudar a entender a jornada dos heróis, uma vez que o herói, além de ser elemento da cultura organizacional, pode ser uma peça fundamental para a sobrevivência das mesmas. Assim, o herói é a pessoa que lidera as ações, luta pela sua comunidade e serve de motivação para os demais seguirem seu caminho, faz com que as pessoas se identifiquem com ele e com a sua luta e vira um modelo de comportamento, uma simbolização da cultura da organização para o mundo exterior. Segundo Freitas (1991), os heróis possuem funções dentro da cultura organizacional, quando se tornam o sucesso atingível e humano e outros membros podem seguir seus exemplos; quando fornecem modelos e simbolizam a organização para o mundo exterior; quando preservam o que a organização tem de especial e estabelecem padrões de desempenho; e quando motivam os empregados e fornecem uma influência duradoura. Os heróis ensinam, inspiram e auxiliam os outros a tentarem seguir seus passos através da sua jornada.

\title{
A identificação dos heróis e suas jornadas
}

Para identificar os heróis das três organizações, foram realizadas perguntas às mesmas pessoas já entrevistadas anteriormente, em cada organização. Os questionamentos buscaram identificar os indivíduos que fizeram 

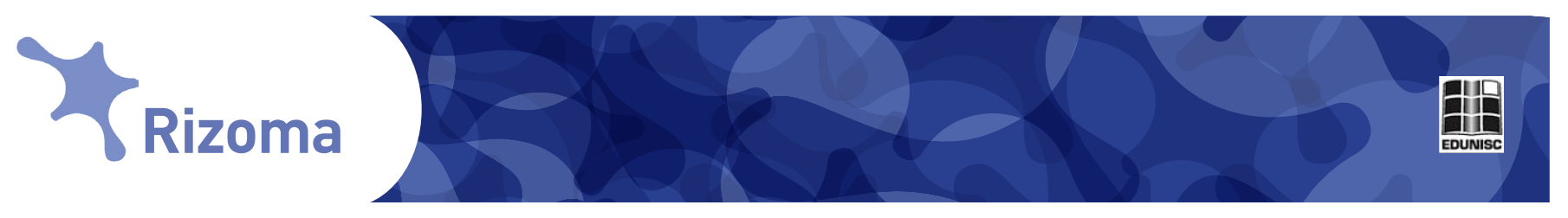

com que cada entrevistado sentisse vontade de participar das organizações do terceiro setor, ou os indivíduos que admirassem pelo trabalho que desenvolvem. Com isso, pretendia-se confirmar o herói organizacional já identificado, de forma preliminar, nas observações participantes e entrevistas em profundidade que abordaram a cultura organizacional.

Na Apata, a voluntária Maria e a adotante Ana, quando questionadas se houve alguém em especial que as fez sentirem vontade de participar da organização, responderam que não houve ninguém em especial. Questionada se havia alguém que admirasse pelo trabalho que faz na organização, Maria deu a seguinte resposta:

Na verdade, sei que parece clichê, mas todos me inspiram, cada um de um modo. Tem alguns que são melhores para alguma coisa e outros para outras. Todo mundo faz uma parte do trabalho que resulta no objetivo final, que é ajudar os animais abandonados e maltratados.

Questionada se ela pensa que essas pessoas fizeram ou fazem algo que ninguém faria, Maria explica:

Falando de um modo geral então já que não tem ninguém específico, as pessoas têm uma visão distorcida do que é uma ONG. Elas acham que é uma empresa que gera lucros e que temos a obrigação de atender qualquer caso que envolva algum animal. Mas elas mesmas não fazem nada para ajudar aquele bichinho, só jogam a responsabilidade em cima da Apata. No último brique que fizemos, os voluntários se encontraram às $5 \mathrm{~h} 45 \mathrm{de}$ sábado para começar a organizar todos os produtos nas bancas para poder iniciar o evento às $8 \mathrm{~h}$. E isso é algo que fazemos que quase ninguém mais faria, pois sabemos que o pagamento não está no dinheiro, mas na satisfação de fazer algo por outro ser.

Desta forma, pode-se perceber que na Apata não há uma pessoa específica que possa ser identificada como um herói organizacional, mas sim todo o grupo de voluntários. Os membros do grupo, como um todo, podem ser identificados como heróis, que segundo Hofstede (2003, p. 22) "são pessoas $[. .$.$] que possuem características altamente valorizadas numa determi-$ nada cultura e por isso servem de modelos de comportamento".

No Lar Colmeia, a mãe social Marta diz que o casal Jerylin e Ken Bayer foi quem a motivou a conhecer o lar e iniciar seu trabalho. Ela disse que o diretor Renato é a pessoa que ela admira pelo trabalho que faz. Ela diz que embora ele seja o "chefe", está sempre disponível para o Lar. Exemplifica dizendo que "se ligar para ele à meia-noite, ele atende". Já a menina Sara diz que compararia os pais sociais com os verdadeiros "heróis de filmes", pois eles dão muito amor e carinho, e diz que precisam ser muito corajosos para aceitar trabalhar no Lar e cuidar dessas crianças.

Pode-se identificar que no Lar Colmeia o diretor Ricardo é um herói organizacional para a mãe social, e que o casal de pais sociais são os heróis para a menina Sara. Ambos desenvolvem um trabalho que é admirado 

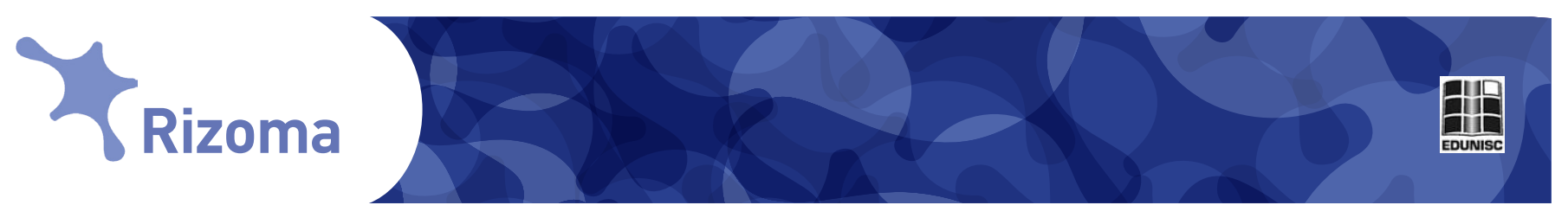

pelas pessoas e motivam os valores preconizados pela organização. Assim, percebe-se que é possível em uma organização haver mais de um herói e que eles, não necessariamente, precisam ser hierarquizados.

[...] eles demonstram como o sucesso pode ser humano e atingível, fornecem um modelo de comportamento, simbolizam a organização para o mundo exterior, preservam o que a organização tem de especial, estabelecem padrões de desempenho e exercem uma influência duradoura que motiva os empregados. Eles personificam os valores e condensam a força e a coragem organizacionais. (FREITAS, 2012, p. 21-2).

No Projeto Criança Cidadã , os pais de João, o casal Simone e Pedro, dizem que quem os motivou a participar do projeto foi o casal Bruna e Renato. Os pais ainda informam que o casal que administra o projeto é quem eles admiram pelo trabalho que fazem, pois sem muito recursos fazem muito pelas crianças atendidas. Já João, admira muito o professor de futebol, pois o considera uma pessoa muito legal.

Pode-se identificar que no Projeto Criança Cidadã̃, o professor seja reconhecido como um herói para a criança, e que o casal que administra o projeto seja visto como herói organizacional para a família desta criança. É o mesmo caso do Lar Colmeia, no qual foram identificados mais de um herói organizacional. Conforme Fleury $(1987$, p. 15) "são das estórias sobre os atos de coragem, que nascem os heróis, que personificam os valores e proveem modelos de comportamento para os demais".

Para identificar a jornada percorrida pelos heróis das organizações analisadas e buscar semelhanças entre suas histórias pessoais e profissionais, foi realizada uma entrevista com pelo menos um herói identificado em cada organização. A escolha se deu pelos pesquisadores deste trabalho. O questionário foi desenvolvido com base nos conceitos de Joseph Campbell (2003, 2007), que afirma que todos os heróis seguem essa estrutura de jornada, pelo menos em algum grau.

Como não houve a identificação de nenhum herói dentro da Apata, optou-se por entrevistar a Elisabete, voluntária que está na organização desde sua fundação e auxiliou na sua criação. Ricardo, do Lar Colmeia, foi entrevistado, pois foi identificado pela mãe social como o herói organizacional. O casal Renato e Bruna, do Projeto Criança Cidadã , foi entrevistado pois foram identificados pelos pais da criança atendida pelo projeto como os heróis organizacionais do Projeto Criança Cidadã.

A primeira entrevistada, Elisabete, é voluntária e uma das fundadoras da Apata. Em 2003, juntamente com alguns amigos, decidiu fundar uma entidade de proteção animal. Ela afirma que possuía esse sonho há muito tempo e sempre conversava com os amigos sobre o assunto. Com o tempo, esse sonho foi criando forma e esse grupo de amigos fundou a Apata. Desde então, ela nunca se afastou da entidade e trabalha arduamente por esta causa.

Questionada se no início houve dúvidas de que daria certo, ela imaginava que tudo poderia dar errado, mas a vontade era muito grande e o grupo estava sólido. Naquele momento o grupo também teve apoio da Prefeitura, o que encorajou e fez os idealizadores acreditarem que era possível. Com 

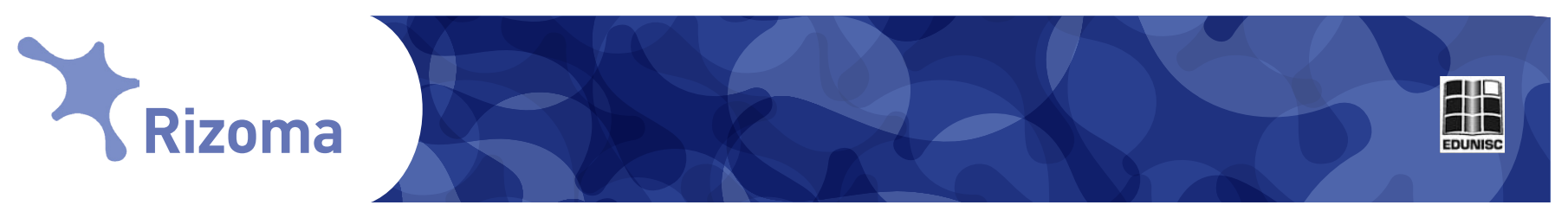

este relato, pode-se identificar que não houve uma recusa inicial ao chamado, mas que houve muitas dúvidas que a fizeram questionar-se. Conforme Campbell (2003, p. 33):

[...] o chamado à aventura significa que o destino convocou o herói e transferiu o seu centro espiritual de gravidade do âmbito da sociedade para uma região desconhecida. Essa região profética de tesouros e perigos pode ser representada de várias formas: como terra distante, uma floresta, um reino subterrâneo, um local situado sob as ondas do mar ou acima do céu, uma ilha secreta, um importante pico de montanha ou um profundo estado onírico. Mas sempre é um local habitado por seres estranhamente fluidos e polimorfos, de tormentos inimagináveis, de feitos sobre-humanos e de prazeres impossíveis.

Ela afirma que uma das voluntárias que ajudou a fundar a associação fez aceitar o desafio. Essa pessoa pode ser identificada como o seu mentor, que a auxiliou durante sua jornada. Relatando os problemas iniciais, que foram revertidos em êxito, e que a fizeram acreditar que seria possível, Elisabete revela casos de animais recolhidos, muitas vezes em caso terminal, que foram curados e encontraram uma família. Além disso, ver depósitos na conta bancária da entidade, sem saber de onde vêm, é outro motivo de satisfação. Questionada se em algum momento achou que tudo estivesse perdido, ela afirma que sim, e relata que neste exato momento, a Apata está passando por uma crise financeira monstruosa. Sobre os problemas ou provações, Campbell (2007, p. 241-242) relata que "além do limiar, então, o herói inicia uma jornada por um mundo de forças desconhecidas e, não obstante, estranhamente íntimas, algumas das quais o ameaçam fortemente (provas), ao passo que outras the oferecem uma ajuda mágica". Por fim, relatando como se sente recompensada, Elisabete diz que o pagamento é o amor dos animais. Sobre a recompensa, Campbell (2014, p. 167) afirma: "a aventura é a sua recompensa, mas é necessariamente perigosa, incluindo possibilidades tanto negativas quanto positivas, umas e outras fora de controle".

O segundo entrevistado, Ricardo, é atualmente diretor executivo do Lar Colmeia. Falando sobre sua história de vida pessoal e profissional, Ricardo relata que aos seis anos de idade foi entregue por sua família biológica para viver com uma família que tivesse mais condições. Depois de aposentado, em 2006, Ricardo foi convidado pelos fundadores do Lar Colmeia e pelos pastores da igreja, o casal canadense Jerylin e Ken Bayer, para trabalhar no Lar como um funcionário contratado, exercendo o cargo de coordenador de voluntários. Durante esse período, ele afirma ter se encontrado, pois se relacionava diariamente com crianças que haviam passado por problemas muito parecidos com os que ele enfrentou. Ricardo trabalhou durante um ano nessa posição e então foi convidado a assumir a direção.

A primeira relação que pode ser percebida entre a trajetória de Ricardo e a jornada do herói é a fácil aceitação ao desafio. Ela pode ser relacionada com o histórico pessoal de Ricardo, foi determinante para que ele iniciasse seu trabalho na organização. Com o chamado, pode-se relacionar o convite para trabalhar no Lar, e também o convite a tornar-se diretor. Campbell (2003, p. 19) afirma que: 

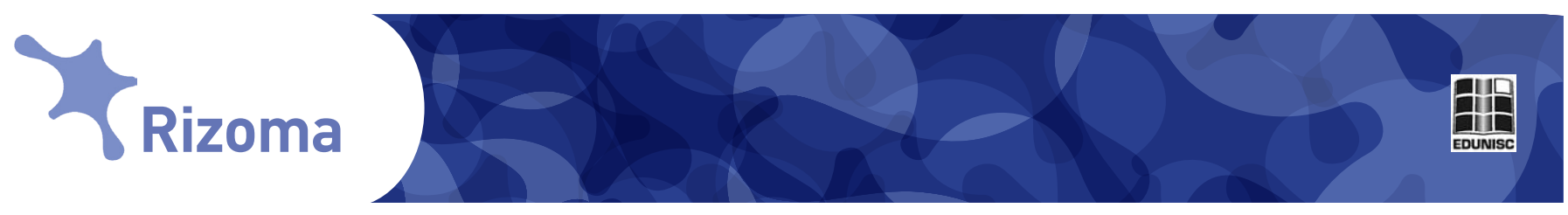

[...] um herói parte do mundo, da vida cotidiana, em direção a uma região de magia sobrenatural: forças fabulosas são encontradas ali e uma vitória decisiva é conquistada; o herói volta de sua misteriosa aventura com o poder de conceder dádivas a seus companheiros.

Para Ricardo, o canadense Ken Bayer foi o seu mentor, em quem ainda hoje se inspira. Sobre as provações, ou seja, os problemas iniciais que sugiram quando ele aceitou esse desafio, e os problemas revertidos em êxito, Ricardo afirma que não passou por nenhum tipo de problema. Questionado sobre como ele se sente recompensado após essa jornada, ele afirma que, para ele, tendo passado por situações parecidas com as dessas crianças e podendo dar a ajuda que ele não teve, é muito gratificante e recompensador.

Os últimos entrevistados são Renato e Bruna, do Projeto Criança Cidadã. Eles são ex-escoteiros, casados e possuem um casal de filhos. Em 2004, Renato participou de uma missão em uma reserva indígena no Amazonas com o movimento escoteiro e, na ocasião, ele foi convidado a se tornar coordenador de um projeto social que havia nesta reserva. Porém, com Bruna no Rio Grande do Sul, prestes a dar à luz a segunda filha do casal, ele recusou o convite. Sobre essa recusa, Campbell (2007) explica que, "com frequência, na vida real, e com não menos frequência, nos mitos ${ }^{9}$ e contos populares, encontramos o triste caso do chamado que não obtém resposta; pois sempre é possível desviar a atenção para outros interesses" (CAMPBELL, 2007, p. 66).

Sob a influência de um amigo, que coordenava o projeto no Amazonas, Renato e Bruna começaram a fazer oficinas para crianças nos sábados à tarde na garagem de sua casa. Com o tempo, decidiram criar o Projeto Criança Cidadã. Largaram seus empregos, deixaram o movimento escoteiro e encontraram um local maior, criando então a sede do projeto. Com este relato, pode-se identificar que o mundo comum para o casal era sua vida antes de investir na iniciativa. Renato afirma que seu grande mentor foi o amigo que o inspirou a criar o Criança Cidadã e quem ele admira muito pelo trabalho social que desenvolveu. Sobre os problemas iniciais, o casal afirma que houve muitos, desde falta de dinheiro, até pessoas se opondo à ideia. Estas foram as provações iniciais que os fizeram questionar-se sobre se realmente deveriam iniciar o projeto. Campbell $(2003$, p. 51) fala destas provações: "uma vez transpondo o portal, o herói percorre uma paisagem onírica de formas curiosamente fluidas, ambíguas, onde deve sobreviver a uma sucessão de provas".

Eles também relataram que a provação mais difícil e traumática foi quando a Prefeitura, o Conselho Tutelar e a Vigilância Sanitária visitaram o projeto com a intenção de fechar a entidade por uma série de não conformidades. Porém, o casal conseguiu regularizar a situação e seguir as normas estabelecidas. Questionados sobre a recompensa, o casal afirma que a grande gratificação é ver que as crianças saem do projeto muito diferentes de quando chegaram, pois absorvem os ensinamentos. Isto faz com que o casal, o herói organizacional, sinta-se com o dever cumprido.
9 [...] a abertura secreta através da qual as inexauríveis energias do cosmos penetram nas manifestações culturais humanas. As religiões, filosofias, artes, formas sociais do homem primitivo e histórico, descobertas fundamentais da ciência e da tecnologia e os próprios sonhos que nos povoam o sono surgem do círculo básico e mágico do mito.

(CAMPBELL, 2007, p. 15). 

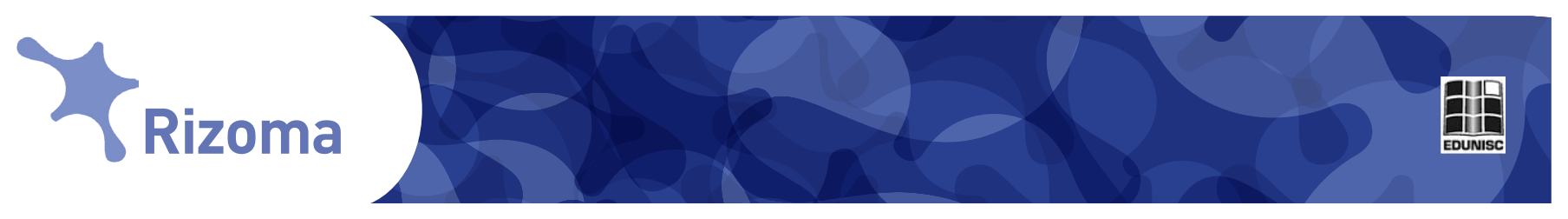

Campbell (2014, p. 131) afirma que "o herói é alguém que deu a própria vida por algo maior que ele mesmo" e que essa abdicação é "[...] quando deixamos de pensar prioritariamente em nós mesmos e em nossa autopreservação, passamos por uma transformação de consciência verdadeiramente heroica" (CAMPBELL, 2014, p. 134). Assim, percebe-se que esta pode ser a realidade diária dos heróis do terceiro setor. Pessoas comuns que atingiram um nível de consciência social e coletiva diferente dos demais e que atualmente são exemplos a serem admirados e seguidos.

Comparando os heróis organizacionais entrevistados, pode-se identificar que Ricardo (Lar Colmeia) e Renato (Projeto Criança Cidadã) possuem um histórico que pode ter influenciado suas trajetórias, para que viessem a trabalhar em organizações do terceiro setor e exercessem o papel de heróis para outras pessoas. Bruna e Renato, assim como Elisabete, enfrentaram diversos problemas para manter suas organizações, passaram por momentos turbulentos, assim como momentos recompensadores. Os três acreditam que a maior recompensa de seu trabalho está em ver sua missão sendo cumprida, trazendo benefícios para as crianças e os animais que eles buscam proteger e auxiliar.

Título: Quadro comparativo das entidades

\begin{tabular}{|l|l|l|l|l|l|}
\hline $\begin{array}{l}\text { Organizações } \\
\text { do terceiro setor }\end{array}$ & $\begin{array}{l}\text { Identificação } \\
\text { do herói }\end{array}$ & $\begin{array}{l}\text { Chamado e } \\
\text { histórico }\end{array}$ & Mentor & $\begin{array}{l}\text { Problemas e } \\
\text { provações }\end{array}$ & Recompensas \\
\hline Apata & $\begin{array}{l}\text { Não há apenas } \\
\text { um herói identi- } \\
\text { ficado }\end{array}$ & $\begin{array}{l}\text { A entrevistada } \\
\text { atendeu ao cha- } \\
\text { mado, mas não } \\
\text { tem histórico } \\
\text { para a trajetória. }\end{array}$ & Houve & $\begin{array}{l}\text { Constantes } \\
\text { problemas } \\
\text { financeiros }\end{array}$ & $\begin{array}{l}\text { Houve - a } \\
\text { recuperação } \\
\text { dos animais }\end{array}$ \\
\hline Lar Colmeia & $\begin{array}{l}\text { Há mais de um } \\
\text { herói identifica- } \\
\text { do: o diretor e } \\
\text { os pais sociais }\end{array}$ & $\begin{array}{l}\text { O entrevista- } \\
\text { do atendeu ao } \\
\text { chamado e tem } \\
\text { histórico para ter } \\
\text { aceito a trajetória }\end{array}$ & Houve & $\begin{array}{l}\text { Preconceito } \\
\text { com as crianças }\end{array}$ & $\begin{array}{l}\text { consanças que } \\
\text { pasam pelo } \\
\text { mesmo proble- } \\
\text { ma do herói }\end{array}$ \\
\hline $\begin{array}{l}\text { Projeto Criança } \\
\text { Cidadã }\end{array}$ & $\begin{array}{l}\text { Há mais de um } \\
\text { herói identifi- } \\
\text { cado: o casal } \\
\text { fundador e o } \\
\text { professor }\end{array}$ & $\begin{array}{l}\text { Recusou o pri- } \\
\text { meiro chamado } \\
\text { e tem histórico } \\
\text { para ter aceito a } \\
\text { trajetória }\end{array}$ & Houve & $\begin{array}{l}\text { foune } \\
\text { froblemanceiros e } \\
\text { condições de } \\
\text { funcionamento } \\
\text { do espaço }\end{array}$ & $\begin{array}{l}\text { Houve - regu- } \\
\text { larização para } \\
\text { funcionamento } \\
\text { do espaço }\end{array}$ \\
\hline
\end{tabular}

Fonte: Elaborado pelos autores

\section{Considerações finais}

O trabalho desenvolvido permitiu ampliar os conhecimentos acerca do papel do herói organizacional em organizações do terceiro setor. Com esta pesquisa, foi possível perceber que as organizações do terceiro setor no Brasil enfrentam inúmeras dificuldades e não recebem muito auxílio fi- 

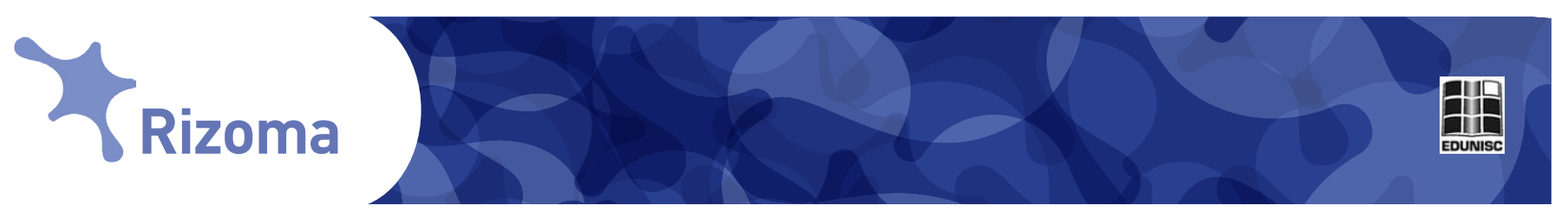

nanceiro e apoio de voluntários. Identificou-se que a cultura organizacional mostra, através de alguns elementos simbólicos, o que é a organização e quais seus principais valores. Por fim, constatou-se que os heróis, elementos da cultura organizacional, são pessoas comuns, que seguiram por um caminho um pouco diferente dos demais, abdicando, muitas vezes, de suas próprias vidas em benefício de outras.

Além disso, identificou-se que o herói organizacional, dentro da cultura da organização, pode ter sido parte da criação da organização, da direção ou também do grupo de voluntários ou colaboradores da organização. O herói do terceiro setor pode ser identificado de várias formas e ainda podem existir mais de um em uma mesma organização. Alguns desses heróis possuem um histórico pessoal que foi determinante para que eles desenvolvessem esse papel social, e também possuem uma trajetória bastante parecida, tendo passado por dúvidas, dificuldades e recompensas com o trabalho que desenvolvem.

Por fim, foi possível perceber, também, que o papel do herói organizacional do terceiro setor é o de incentivador, motivando e servindo como um exemplo a ser seguido dentro das organizações, transmitindo a todos a cultura da organização e reforçando seus valores. Esses heróis buscam reais benefícios para suas comunidades, e enfrentaram, como ainda enfrentam, dificuldades para chegar a esse objetivo. Eles abdicaram, muitas vezes, de suas próprias vidas e de seu tempo, em busca de um objetivo maior, transformando-se assim, em verdadeiros heróis.

\section{Referências}

CAMARGO, M. F. de; SUZUKI, F. M.; UEDA, Mery; SAKIMA, R. Y.; GHOBRIL, A. N. Gestão do Terceiro Setor no Brasil: estratégia de captação de recursos para organizações sem fins lucrativos. São Paulo: Futura, 2001.

CAMPBELL, Joseph. A jornada do herói: vida e obra. São Paulo: Ágora, 2003.

. O herói de mil faces. São Paulo, SP: Pensamento, 2007.

; MOYERS, Bill. O poder do mito. 30. ed. São Paulo, SP: Palas Athena, 2014.

FERNANDES, Rubem César. Privado porém púbico, o Terceiro Setor na América Latina. Rio de Janeiro: Relume Drumará, 1994.

FLEURY, Maria Tereza Leme. Estórias, mitos, heróis - cultura organizacional e relações de trabalho. In: Revista de Administração de Empresas. Vol. 27, n. 4, out./dez., 1987, pp. 7-18. 

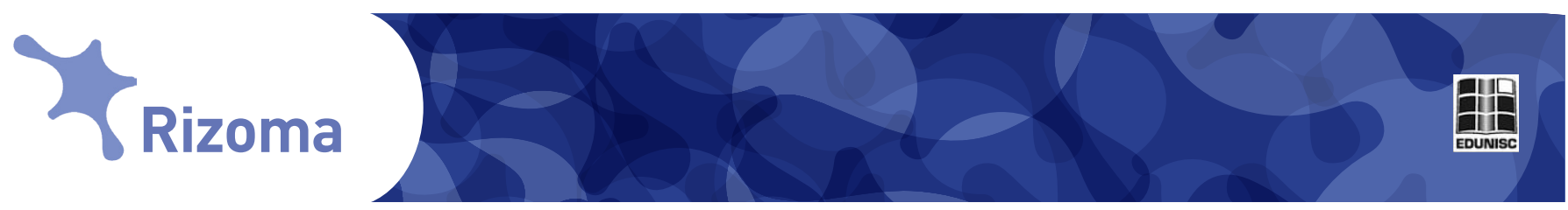

FREITAS, Maria Ester de. Cultura Organizacional: formação, tipologias e impacto. São Paulo: Makron/McGraw-Hill, 1991.

Cultura organizacional: evolução e crítica. São Paulo: Cengage

Learnin, 2012.

HOFSTEDE, Geert. Culturas e organizações: compreender a nossa programação mental. 1. ed. Lisboa: Sílabo, 2003.

PERUZZO, Cicilia M. K. Comunicação comunitária e gestão participativa. In: KUNSCH, M. M. Krohling; KUNSCH, W. L. Relações Públicas Comunitárias: a comunicação em uma perspectiva dialógica e transformadora. São Paulo: Summus, 2007. 